\title{
Routine testing for PALB2 mutations in familial pancreatic cancer families and breast cancer families with pancreatic cancer is not indicated
}

\author{
Femme Harinck ${ }^{\star, 1}$, Irma Kluijt ${ }^{2}$, Saskia E van $\mathrm{Mil}^{3}$, Quinten Waisfisz ${ }^{3}$, Theo AM van $\mathrm{Os}^{4}$, Cora M Aalfs ${ }^{4}$, \\ Anja Wagner ${ }^{5}$, Maran Olderode-Berends ${ }^{6}$, Rolf H Sijmons ${ }^{6}$, Ernst J Kuipers ${ }^{1,7}$, Jan-Werner Poley ${ }^{1}$, \\ Paul Fockens ${ }^{8}$ and Marco J Bruno ${ }^{1}$
}

PALB2-mutation carriers not only have an increased risk for breast cancer $(B C)$ but also for pancreatic cancer (PC). Thus far, PALB2 mutations have been mainly found in PC patients from families affected by both PC and BC. As it is well known that the prevalence of gene mutations varies between different populations, we studied the prevalence of PALB2 mutations in a Dutch cohort of non-BRCA1/2 familial PC (FPC) families and in non-BRCA1/2 familial BC (FBC) families with at least one PC case. Mutation analysis included direct sequencing and multiplex ligation-dependent probe amplification (MLPA) and was performed in a total of 64 patients from 56 distinct families (28 FPC families, 28 FBC families). In total, 31 patients (48\%) originated from FPC families; 24 were FPC patients (77\%), 6 had a personal history of BC (19\%) and 1 was a suspected carrier (3.2\%). The remaining 33 patients (52\%) were all female BC patients of whom 31 (94\%) had a family history of PC and 2 (6.1\%) had a personal history of PC. In none of these 64 patients a PALB2 mutation was found. Therefore, PALB2 does not have a major causal role in familial clustering of $P C$ and $B C$ in non-BRCA1/2 families in the Dutch population.

European Journal of Human Genetics (2012) 20, 577-579; doi:10.1038/ejhg.2011.226; published online 14 December 2011

Keywords: familial pancreatic cancer; pancreatic cancer susceptibility; breast cancer susceptibility; mutation analysis; hereditary cancer

\section{INTRODUCTION}

Recently, it has become clear that the Fanconi gene FANCN/PALB2 (partner and localizer of BRCA2) should not only be considered as a susceptibility gene for breast cancer $(\mathrm{BC})^{1}$ but also as a susceptibility gene for pancreatic cancer (PC). ${ }^{2}$ Mutations in this gene may be associated with familial clustering of PC and BC. ${ }^{1-10}$

Previous studies have shown that PALB2-mutation-positive familial $\mathrm{BC}(\mathrm{FBC})$ patients were significantly more likely to have a relative with $\mathrm{PC},{ }^{5}$ and that nearly all $P A L B 2$-mutation positive familial PC (FPC) families were affected by at least one BC case. ${ }^{4}$

Given these findings and the fact that the prevalence of gene mutations varies between different populations, we aimed to determine the prevalence of PALB2 mutations in Dutch cohorts of non-BRCA1/2 FPC patients and of non-BRCA1/2 FBC patients with a personal or family history of PC.

\section{MATERIALS AND METHODS}

The prevalence of germline mutations in PALB2 was investigated in Dutch non$B R C A 1 / 2$ FPC patients and non-BRCA1/2 FBC patients with a personal or family history of PC.

FPC families were defined as families with PC in either $\geq 2$ first-degree relatives (FDRs), $\geq 3$ relatives (FDR and second-degree relative (SDR)) or 2
SDRs of whom one was $<50$ years at diagnosis and did not meet diagnostic criteria of specific other cancer syndromes. ${ }^{11}$ These families were identified in the registries of the Clinical Genetic Centres of Amsterdam (Academic Medical Centre-University Medical Centre Amsterdam and Netherlands Cancer Institute), Rotterdam (Erasmus MC-University Medical Centre Rotterdam), and Groningen (University Medical Centre Groningen), consisting of a total of 40 FPC families. In 28 of these families, DNA was available for PALB2 mutation analysis. In families in which DNA was available of multiple family members affected by PC, PALB2 mutation analysis was performed in DNA of all cases. In families without available DNA from PC patients, mutation analysis was performed in family members affected by BC. In one family, mutation analysis was performed in a suspected carrier; this suspicion was based on the position of this individual in the pedigree; this specific case had a sibling with PC and a child with PC.

The FBC patients were taken from the registry from the Netherlands Cancer Institute and consisted of non- $B R C A 1 / 2 \mathrm{BC}$ patients that fulfilled the Dutch clinical criteria for BRCA1 and BRCA2 mutation testing, which include (1) BC diagnosis at age $<35$ years, (2) bilateral $\mathrm{BC}$ of which one diagnosis at age $<50$ years, (3) at least two FDR with BC at an age $<50$ years, (4) at least three FDR or SDR with $\mathrm{BC}$, and (5) one $<50$ years at diagnosis. From this registry, patients with a personal history of both $\mathrm{BC}$ and $\mathrm{PC}$, and $\mathrm{BC}$ patients with a FDR or SDR with PC were selected. In families in which DNA was available of multiple affected family members, PALB2 mutation analysis was performed in all cases.

\footnotetext{
${ }^{1}$ Department of Gastroenterology and Hepatology, Erasmus MC, University Medical Centre Rotterdam, Rotterdam, The Netherlands; ${ }^{2}$ Familial Cancer Clinic, The Netherlands Cancer Institute Amsterdam, Amsterdam, The Netherlands; ${ }^{3}$ Department of Clinical Genetics: Section Oncogenetics, VU University Medical Centre, Amsterdam, The Netherlands; ${ }^{4}$ Department of Clinical Genetics, Academic Medical Centre, University of Amsterdam, Amsterdam, The Netherlands; ${ }^{5}$ Department of Clinical Genetics, Erasmus MC, University Medical Centre Rotterdam, Rotterdam, The Netherlands; ${ }^{6}$ Department of Genetics, University of Groningen, University Medical Centre Groningen, Groningen, The Netherlands; ${ }^{7}$ Department of Internal Medicine, Erasmus MC, University Medical Centre Rotterdam, Rotterdam, The Netherlands; ${ }^{8}$ Department of Gastroenterology and Hepatology, Academic Medical Centre, University of Amsterdam, Amsterdam, The Netherlands

*Correspondence: Dr F Harinck, Erasmus MC-University Medical Centre Rotterdam, Department of Gastroenterology and Hepatology, 's-Gravendijkwal 230, 3015 CE Rotterdam, The Netherlands. Tel: +31 (0)10 7032825; Fax: +31 (0)10 7034682; E-mail: f.harinck@erasmusmc.nl
}

Received 10 August 2011; revised 24 October 2011; accepted 26 October 2011; published online 14 December 2011 
At the time of genetic counselling, patients had given written informed consent to use their DNA for the search for new cancersusceptibility genes.

Table 1 Characteristics of tested families $(n=56)$ and cases $(n=64)$

\begin{tabular}{lrr}
\hline & $n$ & $\%$ \\
\hline FPC families $\mathrm{n}=28$ & 31 & \\
$\quad$ Total number of cases tested & & \\
$\quad$ Type of case in whom PALB2 mutation analysis was performed & 24 & 77 \\
$\quad$ Personal history of FPC & 6 & 19 \\
$\quad$ Personal history of BC & 1 & 3.2 \\
$\quad$ Suspected carrier & & \\
& & \\
BC-PC family $\mathrm{n}=28$ & 33 & \\
Total number of cases tested & 31 & 94 \\
$\quad$ Type of case in whom PALB2 mutation analysis was performed & 2 & 6.1 \\
$\quad$ Personal history of BC with FDR or SDR with PC & & \\
$\quad$ Personal history of both BC and PC & 6 & 21 \\
Type of Dutch clinical criteria for BRCA1/2 mutation testing per family & 2 & 7.1 \\
$\quad$ BC diagnosis at age $<35$ years & 12 & 43 \\
$\quad$ Bilateral BC, one diagnosis at age $<50$ years & 8 & 29 \\
$\quad \geq 2$ FDR with BC at age <50 years \\
$\quad 3$ FDR or SDR with BC, one <50 years at diagnosis
\end{tabular}

Table 2 Detailed description of FPC families $(n=28)$ and PC-affected FBC families

\begin{tabular}{lll}
\hline FPC families $\mathrm{n}=28$ & & \\
Total number of PC cases ( $n$ ) & 70 & \\
Confirmed by medical or pathology report $(n, \%)$ & 57 & 81 \\
Mean age at PC diagnosis (years, SD) & 61 & 11.5 \\
Mean age at PC diagnosis in tested case $n=24$ (years, SD) & 60 & 11.4 \\
Male gender of PC case $(n, \%)$ & 38 & 54 \\
Number of families $\geq 3$ family members diagnosed with PC $(n, \%)$ & 10 & 36 \\
Number of families affected by BC $(n, \%)$ & 14 & 50 \\
& & \\
BC-PC families $\mathrm{n}=28$ and cases $\mathrm{n}=33$ & & \\
Mean age at BC diagnosis in tested case (years, SD) & 42 & 9.5 \\
Total number of PC cases $(n)$ & 29 & \\
Confirmed by medical or pathology report $(n, \%)$ & 24 & 83 \\
Mean age at PC diagnosis (years, SD) & 70 & 11.9 \\
Male gender of PC case $(n, \%)$ & 12 & 41
\end{tabular}

Table 3 Overview of literature on role of PALB2 mutations in FPC and in BC families affected by PC

\begin{tabular}{|c|c|c|c|c|c|c|}
\hline \multicolumn{7}{|c|}{ Role of PALB2 mutations in FPC } \\
\hline \multirow[b]{3}{*}{ Study } & \multirow[b]{3}{*}{ Country } & \multirow{3}{*}{$\begin{array}{c}\text { Total } \\
\mathrm{n}\end{array}$} & \multirow{3}{*}{$\begin{array}{l}\text { Population (familie } \\
\text { FPC } \\
\mathrm{n}\end{array}$} & \multirow{3}{*}{$\begin{array}{c}F P C \text { with } B C \\
\mathrm{n}\end{array}$} & \multirow{3}{*}{$\begin{array}{l}\text { PALB2+families } \\
\mathrm{n}(\%, 95 \% \mathrm{Cl})\end{array}$} & \multirow[b]{3}{*}{ PALB2+families with $B C$} \\
\hline & & & & & & \\
\hline & & & & & & \\
\hline Jones $^{2}$ & USA & 96 & 96 & n.s. & $3(3.1$, n.s. $)$ & $2 / 3(75 \%)$ \\
\hline Tischkowitsh ${ }^{4}$ & Canada & 101 & 80 & 21 & $1(1.0$, n.s. $)$ & $1 / 1(100 \%)$ \\
\hline Slater ${ }^{10}$ & Europe & 81 & 67 & 15 & $3(3.7,0.8-10.4 \%)$ & $3 / 3(100 \%)$ \\
\hline Current study & The Netherlands & 28 & 14 & 14 & $0(0$, n.a. $)$ & n.a. \\
\hline \multicolumn{7}{|c|}{ Role of PALB2 mutations in BC families affected by $P C$} \\
\hline & & \multicolumn{3}{|c|}{ Population (families) } & \multicolumn{2}{|l|}{ PALB2+families } \\
\hline & & Total & Pers. $H \times B C$ and F/SDR PC & Pers. $H x B C$ and $P C$ & & \\
\hline Study & Country & $\mathrm{n}$ & $\mathrm{n}$ & $\mathrm{n}$ & $\mathrm{n}(\%, 95 \% \mathrm{Cl})$ & \\
\hline Adank $^{14}$ & The Netherlands & 45 & 45 & 0 & $0(0$, n.a. $)$ & \\
\hline Peterlongo ${ }^{8}$ & Italy & 62 & 62 & 0 & $3(4.8,0.99-13.29 \%)$ & \\
\hline Stadler $^{9}$ & USA & 77 & 55 & 22 & $0(0$, n.a. $)$ & \\
\hline Hofstatter ${ }^{7}$ & USA & 94 & 91 & 3 & $2(2.1,0.4-6.5 \%)$ & \\
\hline Current study & The Netherlands & 28 & 26 & 2 & $0 / 28(0 \%)$ & \\
\hline
\end{tabular}

Sequencing and multiplex ligation-dependent probe amplification (MLPA)

The presence of germline mutations in PALB2 was evaluated by direct sequencing of the entire coding region and by sequencing intron-exon boundaries on genomic DNA isolated from whole blood. Primer pairs that were used have been previously described. ${ }^{12}$

The presence of large genomic deletions in PALB2 was analysed by MLPA using the MLPA P057 kit of MRC-Holland (Amsterdam, The Netherlands) as previously described. ${ }^{13}$ As a positive control, genomic DNA from the previously described PALB2 FA patient EUFA1341 was included in the analysis. ${ }^{12}$

\section{RESULTS}

PALB2 mutation analysis was performed in a total of 64 patients from 56 distinct families (28 FPC families, 28 FBC families; Table 1). In total, 31 patients (48\%) originated from FPC families; 24 were FPC patients (77\%), 6 had a personal history of BC (19\%) and 1 was a suspected carrier $(3.2 \%)$. The remaining 33 patients $(52 \%)$ were all female BC patients of whom 31 (94\%) had a family history of PC and $2(6.1 \%)$ had a personal history of PC.

The 28 FPC families had a total of 70 affected patients with PC of which $57(81 \%)$ were confirmed by medical $(n=11)$ or pathology reports $(n=46)$ (Table 2$)$. The mean age at time of PC diagnosis was 61 years $(\mathrm{SD} \pm 11.5)$. In total, 38 of the PC patients $(54 \%)$ were male. Ten FPC families $(36 \%)$ had at least three family members diagnosed with PC. Fourteen FPC families (50\%) were affected by BC. Among the 33 tested patients from 28 FBC families, the mean age at $\mathrm{BC}$ diagnosis was 42 years ( $\mathrm{SD} \pm 9.5)$. The total number of $\mathrm{PC}$ cases was 29 , of which $24(83 \%)$ were confirmed by medical $(n=13)$ or pathology report $(n=11)$. The mean age at PC diagnosis was 70 years $(\mathrm{SD} \pm 10.9)$ and $41 \%(n=12)$ of all PC cases were male.

In none of these cases was a PALB2 mutation found by direct sequencing and MLPA.

\section{DISCUSSION}

Our data provide further evidence that there is a limited causal role for PALB2 mutations in both FPC and FBC, as we did not identify any PALB2 mutations in our Dutch cohort of 28 FPC families and 28 FBC families affected with at least one case of PC.

Since the recent recognition of PALB2 as BC- and PC-susceptibility gene, ${ }^{1,2}$ a number of studies have been carried out to investigate the role

Abbreviations: n.a., not applicable; n.s., not specified. 
of PALB2 in different patient populations. Our results are in line with the results of these previous reports in which no PALB2 mutations, ${ }^{9,14}$ or low prevalence of $P A L B 2$ mutations, ${ }^{2,4,7-8,10}$ were found. It should be mentioned that the relatively small sample size could be a possible explanation for that no mutation carrier was identified in the current study. Even if a larger sample size might have detected sporadic cases, its results do show that the role of PALB2 in this particular setting is insignificant. When combining our data with the previously published data, PALB2 is involved in only $2.3 \%$ (7/306, range $0-3.7 \%, 95 \%$ CI $0.6-40 \%$ ) of all FPC families and in $1.6 \%$ (5/306, range $0-4.8 \%$, 95\% CI $0.21-31 \%$ ) of all FBC families with PC cases (Table 3 ).

Although PALB2 is involved in the clustering of both PC and BC, it explains only a small fraction of the clustering, and it is therefore crucial that future research is directed towards identifying the gene(s) that are involved in the development of both FPC and FBC. Knowledge of additional PC- and BC-susceptibility genes will be helpful in the counselling of family members from FPC and FBC families, as this will improve our ability to identify individuals at increased risk of developing PC and BC. Furthermore, it will have implications on the effectiveness of screening which will be highest when only directed towards individuals at risk.

In conclusion, our results provide further evidence for the low prevalence of PALB2 mutations among non-BRCA1/2 FPC families and FBC families with PC cases. Therefore, routine analysis of this gene in these families is not warranted. Future research should be directed towards specifying subtypes of FPC/FBC families in which $P A L B 2$ analysis is useful towards identifying other gene(s) involved in the development of $\mathrm{PC}$ and $\mathrm{BC}$.

\section{CONFLICT OF INTEREST}

The authors declare no conflict of interest.

\section{ACKNOWLEDGEMENTS}

On behalf of the Dutch Research Group of Pancreatic Cancer Surveillance in High-Risk Individuals (in alphabetical order): Amsterdam Medical Center:
Cora M Aalfs, Marcel GW Dijkgraaf, Paul Fockens, Dirk J Gouma, Jeanin E van Hooft, C Yung Nio, Theo AM van Os, Ellen MA Smets. Erasmus Medical Center: Katharina Biermann, Marco J Bruno, Henny van Duijl, Casper HJ van Eijck, Femme Harinck, Nanda Krak, Jan-Werner Poley, Anja Wagner. The Netherlands Cancer Institute-Antoni van Leeuwenhoek Hospital: Eveline MA Bleiker, Annemieke Cats, Irma Kluijt, Anja van Rens, Grace Sidharta, Senno Verhoef. University Medical Center Groningen: Hendrik M van Dullemen, Rolf H Sijmons.

1 Rahman N, Seal S, Thompson D et al: PALB2, which encodes a BRCA2interacting protein, is a breast cancer susceptibility gene. Nat Genet 2007; 39 . 165-167.

2 Jones S, Hruban RH, Kamiyama M et al: Exomic sequencing identifies PALB2 as a pancreatic cancer susceptibility gene. Science 2009; 324: 217.

3 Erkko $\mathrm{H}$, Xia B, Nikkila J et al: A recurrent mutation in PALB2 in Finnish cancer families. Nature 2007; 446: 316-319.

4 Tischkowitz MD, Sabbaghian N, Hamel $\mathrm{N}$ et al: Analysis of the gene coding for the BRCA2-interacting protein PALB2 in familial and sporadic pancreatic cancer. Gastroenterology 2009; 137: 1183-1186.

5 Casadei S, Norquist BM, Walsh T et al: Contribution of inherited mutations in the BRCA2-interacting protein PALB2 to familial breast cancer. Cancer Res 2011; 71: 2222-2229.

6 Hellebrand $\mathrm{H}$, Sutter $\mathrm{C}$, Honisch $\mathrm{E}$ et al: Germline mutations in the PALB2 gene are population specific and occur with low frequencies in familial breast cancer. Hum Mutat 2011; 32: E2176-E2188.

7 Hofstatter EW, Domchek SM, Miron A et al: PALB2 mutations in familial breast and pancreatic cancer. Fam Cancer 2011; 10: 225-231.

8 Peterlongo P, Catucci I, Pasquini G et al: PALB2 germline mutations in familial breast cancer cases with personal and family history of pancreatic cancer. Breast Cancer Res Treat $2011 ; 126: 825-828$

9 Stadler ZK, Salo-Mullen E, Sabbaghian N et al: Germline PALB2 mutation analysis in breast-pancreas cancer families. J Med Genet 2011; 48: 523-525.

10 Slater EP, Langer P, Niemczyk E et al: PALB2 mutations in European familial pancreatic cancer families. Clin Genet 2010; 78: 490-494.

11 Brand RE, Lerch MM, Rubinstein WS et al: Advances in counselling and surveillance of patients at risk for pancreatic cancer. Gut 2007; 56: 1460-1469.

12 Xia B, Dorsman JC, Ameziane $\mathrm{N}$ et al: Fanconi anemia is associated with a defect in the BRCA2 partner PALB2. Nat Genet 2007; 39: 159-161.

13 Ameziane N, van den Ouweland AM, Adank MA et al: Lack of large genomic deletions in BRIP1, PALB2, and FANCD2 genes in BRCA1/2 negative familial breast cancer. Breast Cancer Res Treat 2009; 118: 651-653.

14 Adank MA, van Mil SE, Gille JJ, Waisfisz Q, Meijers-Heijboer H: PALB2 analysis in BRCA2-like families. Breast Cancer Res Treat 2011; 127: 357-362. 